Erratum

\title{
Formation of fermentation products and extracellular protease during anaerobic growth of Bacillus licheniformis in chemostat and batch-culture
}

Ben A. Bulthuis ${ }^{1}$, Caius Rommens, Gregory M. Koningstein, Adriaan H. Stouthamer \& Henk W. van Verseveld* Department of Microbiology, Biological Laboratory, Free University, de Boelelaan 1087, 1081 HV Amsterdam, The Netherlands; (1 present address: Genencor International Inc., 180 Kimball Way, South San Francisco, CA 94080, USA) (*requests for offprints)

Antonie van Leeuwenhoek 60 (3/4): 355-371, 1991

On pages 358 and 359, in the sentence: "Some examples of lower detection limits (50 $\mu$ l sample-injection) at which reliable quantitation is still possible are $20 \mathrm{mM}(R I)$ for glucose and pyruvate, $50 \mathrm{mM}(R I)$ for succinate, lactic, acetic and formic acid and $250 \mathrm{mM}$ for butane-diol, ethanol and glycerol (RI).", the concentration " $\mathrm{mM}$ " (millimolar) should be " $\mu \mathrm{M}$ " (micromolar). 